\title{
Injection moulding and selective metallisation technologies for polymer Microsystems
}

Tenchine, L.; Gout, S.; Dessors, S. ; Azcarate, S.; Tosello, Guido; Calaon, Matteo; Miller, N.; Brown, B. ; Edouard, C.; Müller, T.

Total number of authors:

14

Published in:

Proceedings of the 11th International Conference on Multi-Material Micro Manufacture (4M2016) : co-organised with 10th International Workshop on Microfactories (IWMF2016)

Link to article, DOI:

10.3850/978-981-11-0749-8 688

Publication date:

2016

Document Version

Publisher's PDF, also known as Version of record

Link back to DTU Orbit

Citation (APA):

Tenchine, L., Gout, S., Dessors, S., Azcarate, S., Tosello, G., Calaon, M., Miller, N., Brown, B., Edouard, C., Müller, T., Wittner, W., Prantl, M., SShang, X., \& Batal, A. (2016). Injection moulding and selective metallisation technologies for polymer Microsystems. In Proceedings of the 11th International Conference on Multi-Material Micro Manufacture (4M2016) : co-organised with 10th International Workshop on Microfactories (IWMF2016) (pp. 19-22). Research Publishing Services. https://doi.org/10.3850/978-981-11-0749-8 688

\section{General rights}

Copyright and moral rights for the publications made accessible in the public portal are retained by the authors and/or other copyright owners and it is a condition of accessing publications that users recognise and abide by the legal requirements associated with these rights.

- Users may download and print one copy of any publication from the public portal for the purpose of private study or research.

- You may not further distribute the material or use it for any profit-making activity or commercial gain

- You may freely distribute the URL identifying the publication in the public portal 


\title{
Injection moulding and selective metallisation technologies for polymer Microsystems
}

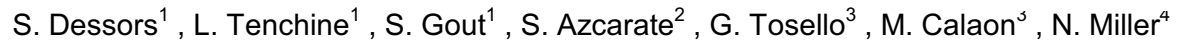 \\ B. Brown ${ }^{4}$, C. Edouard ${ }^{5}$, T. Müller ${ }^{6}$, W. Wittner ${ }^{7}$, M. Prantl ${ }^{8}$, Xiaobang Shang ${ }^{9}$, Afif Batal ${ }^{9}$ \\ ${ }^{1}$ IPC, 2 rue Pierre et Marie Curie, 01100 Bellignat, France \\ ${ }^{2}$ Tekniker, Technological Subdirection, Scientific Director, Iñaki Goenaga 5, 20600 Eibar, Spain \\ ${ }^{3}$ Technical University of Denmark, Department of Manufacturing Engineering, 2800 Kgs. Lyngby, Denmark \\ ${ }^{4}$ Flann Microwave Ltd, Dunmere road, Bodmin, Cornwall, United Kingdom \\ ${ }^{5}$ Flowdit, 2 rue Paul Milleret, 25000 Besançon, France \\ ${ }^{6}$ KIT Karlsruhe Institute of Technology, 76344 Eggenstein-Leopoldshafen, Germany \\ ${ }^{7}$ Ernst Wittner GmbH, Missindorfstrasse 21, 1140 Vienna, Austria \\ ${ }^{8}$ Alicona Imaging GmbH, Optical 3D measurement and inspection, Dr Auner Strasse, 8074 Raaba/Graz, Austria \\ ${ }^{9}$ School of Mechanical Engineering, University of Birmingham, Birmingham, United Kingdom
}

\begin{abstract}
The present paper describes how developing and optimizing high-throughput integrated technologies for the production of miniaturised multi-material and multi-functional components at industrial scale. Based on 2 industrial demonstrators (a band diplexer and a micro aeraulic device), the paper shows that many technologies have to be combined to succeed: injection moulding process, copper plating, laser ablation, laser welding, glue welding...
\end{abstract}

Keywords: Microsystem, plating, LDS, MEMS, injection moulding, laser.

\section{Introduction}

The global market for smart devices and products, involving the innovative combination of Key Enabling Technologies (KETs), has been growing dramatically in recent years. This trend is a direct consequence of the growing needs across a range of industry sectors, e.g. automotive, ICT, medical, consumers, to integrate multiple functions in the smallest, lightest and most cost-efficient possible enclosures/packages by combining the latest advances in micro-replication and assembly processes, new tooling concepts and designs, advanced materials, and high-throughput process chains.

The FP7 project Hinmico is part of this trend. Its main objective is to develop and optimize highthroughput integrated technologies for the production of miniaturised multi-material and multi-functional components at industrial scale. In this paper, the following technologies are discussed, with regards to this objective: injection moulding (including two-shot moulding), polymer metallisation, and polymer parts assembly. Two industrial demonstrators, combining injection moulding and selective metallisation of polymer parts, and developed in the frame of the project, are presented to illustrate the technical innovations.

The first demonstrator is a band diplexer developed by Flann in Cornwall. The diplexer separates, transmit and receive signals allowing radios doing these two tasks at the same time. Performance affects link capacity and link length. There is already a metallic version with a body and a lid. Existing process consists in milling an aluminium block. To reduce production cost, an approach combining injection moulding and selective plating is investigated, and will be compared to the existing solution in terms of performances. Identified challenges are dimensional accuracy, homogeneity of the metal plating (homogenous thickness with $+/-5 \mu \mathrm{m}$ accuracy despite of complex shapes), and assembly (plated surfaces that have to be welded).

The second demonstrator is an innovative micro aeraulic device for automotive industry. A silicon MEMS is used to generate a pulsed air flow. Its architecture is based on a row of micro-valves, actuated by an oscillating structure with interdigitated electrodes. Depending on the electric potential applied on the electrodes, the moving part controls the opening of the micro-valves, enabling an accurate management of the pulsed air-flow. Placed on the upper side of a car boot, the MEMS can efficiently reduce the aerodynamic drag and fuel consumption. The optimized integration of the MEMS in the automotive environment requires the development of a specific packaging solution. A polymer packaging is developed, targeting both cost and weight reduction compared to the existing metallic packaging solution. Packaging development involves several processes: injection moulding, selective metallisation by Laser Direct Structuring (LDS) process, and assembly by laser welding. Main challenges are high level of air tightness (acceptable pressure loss below $10 \mathrm{mbar}$ ) and packaging design that will allow silicone MEMS movements. Fragile silicone MEMS will have to be preserved despite of large difference of CTE between silicone $\left(2,6.10^{-6} \mathrm{~K}^{-1}\right)$ and polymers $\left(50.10^{-6} \mathrm{~K}^{-1}\right)$.

\section{Injection moulding technologies}

\subsection{Polymer parts design}

A version of the band diplexer already exists in aluminum. The objective was to design a plastic part 
with the same functional characteristics regarding the microwaves reception / separation / transmission, but taking into account the limitations related to injection moulding. Optimal compromise must be found between, on one hand, the targeted low tolerances (for instance 5 microns for the flatness) and low roughness (between 0.1 and $0.2 \mu \mathrm{m} \mathrm{Ra}$ ), and on the other hand, the standard design rules for injection moulding: uniform thickness, draft angles, ribs... Functional simulation (microwave transmission / reception / separation) was performed in order to validate the final design of the polymer part.

In the case of the aeraulic MEMS packaging, part design has to meet several requirements. As silicon is a brittle material, the packaging must ensure an appropriate mechanical protection of the MEMS. This is achieved by a combination of soft polymer material and spring-shaped structures. The electrical connection with the MEMS is achieved using metallised polymer cantilevers $(0.75 \mathrm{~mm}$ large, $5.6 \mathrm{~mm}$ long, $0.8 \mathrm{~mm}$ thick). These cantilevers enable the electrical contact with the silicon MEMS surface, in order to drive the mobile structure. The package is designed in order to integrate 4 MEMS side by side.

Rheological studies were performed for both applications to guarantee a good filling in very thin areas (down to $500 \mu \mathrm{m}$ ), to avoid welding lines in functional areas, and also to evaluate the best process parameters that will reduce warpage due to shrinkage.

\subsection{Mould manufacturing}

A single mould was manufactured for both demonstrators, with interchangeable cavities (see Fig. 1). This approach enables:

- a tooling cost reduction

- the possibility to switch easily from band diplexer application to micro aeraulic device (hard or soft material)

- the development and tuning of parallel sets of cavities, thanks to similar frame moulds available at each involved partners location.

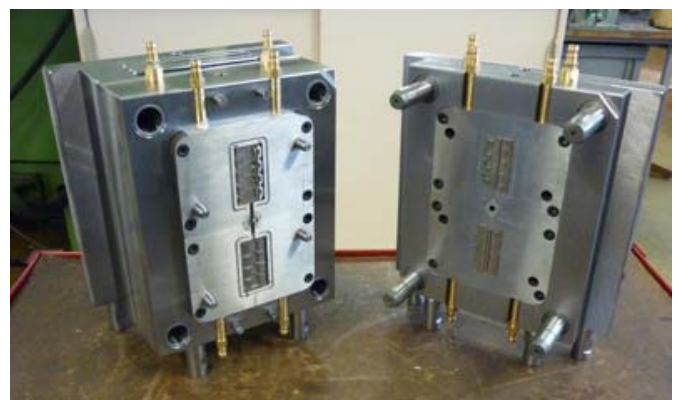

Fig. 1. Mould opened in the micro fluidic device version.

Laser sintering process was used to make conformal cooling channels that guarantee a uniform and optimized temperature control (see Fig. 2). Thanks to this technology, cooling channels are very close to cavity surface. Heating transfers are then improved. Screwed water connections and Viton $\AA$ seals let the possibility to connect the mould to heat\&cool systems (oil or high pressurised water).

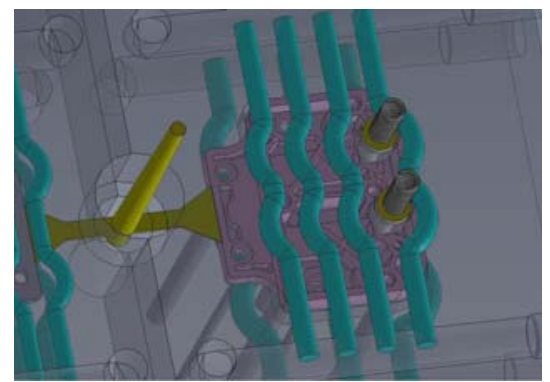

Fig. 2. Diplexer mould Cad data with cooling channels obtained with laser sintering process (blue channels).

\subsection{Material selection}

\subsubsection{Diplexer}

Main requirements for polymer material selection are dimensional accuracy and surface roughness which must be as low as possible. Selected material must also be suitable for plating process. As diplexers will be fixed in electrical boxes placed on buildings roofs (close to antennas), they will be subjected to large temperature variations depending on climatic conditions: the defined range temperature for the material selection is thus from $-20^{\circ} \mathrm{C}$ to $+80^{\circ} \mathrm{C}$. Among plateable polymers, lower coefficients of thermal expansion (CTE) are achieved for LCP (Liquid Cristal Polymer). Two materials were identified for the study: LCP Vectra E840i LDS (40\% mineral filled) compatible with LDS process, and LCP Vectra E820i Pd compatible with total plating process.

\subsubsection{Micro fluidic device}

Regarding micro fluidic device, main specifications are dimensional stability, compatibility with selective plating processes for the housing, air tightness and compatibility with laser welding process. The latter specification implies the selection of a transparent material for laser machine wavelengths (950-1150nm). Several polymer materials satisfy this requirement, and PC was selected for several reasons: hard material, commonly used in automotive industry, easily injected... For the housing, an absorbent material with a good chemical compatibility with $P C$ was selected: ABS/PC. Overmoulding of both plastic parts with a soft material is performed for 2 reasons: good air tightness is required, and the CTE of PC and $A B S / P C$ are not low enough. Furthermore, overmoulding the parts enables the compensation of potential dimensional variations.

Finally, material selection is:

- ABS/PC Xantar C RC 3710 LDS for the housing

- transparent PC Makrolon 2405 for the cover

- SEBS Solplast TH50A-9000D for the overmoulding

\subsection{Injection moulding}

As demonstrated by University College Dublin [1] and Institute for Plastics Processing [2], heat\&cool systems and vacuum improve the filling of cavities with very thin shapes. Injection trials highlighted that vacuum is significant for Hinmico parts, especially for the filling of the cantilevers for the micro aeraulic device application: without vacuum, the injected polymer parts do not meet the technical requirements. 
Process parameters were optimized in order to achieve the quality level expected by Flann and Flowdit on their respective demonstrators. This optimization included: mould temperature, barrel temperature, injection speed and holding pressure.

As the manufacturing of the demonstrators is a multi-step process, direct correlation between parts inspection just after injection moulding (aspect and dimensional measurements) and performances of the parts after plating cannot be easily achieved and requires a specific Design of Experiment (DoE). This study was performed by DTU and KIT to identify the preponderant process parameters and their impact on planarity and plating homogeneity. Details on this DoE are described in another $4 \mathrm{M}$ paper.

\section{Selective metallisation}

There are 4 major processes to make selective metallisation of polymer parts. The two-shots moulding process is one of the most famous and probably the older one [3]. In two-shots MID technology, metal patterning is done by using two different plastic materials - one plateable plastic and one not plateable plastic - for injection moulding followed by a chemical pre-treatment and electroless plating of the standard $\mathrm{Cu} / \mathrm{Ni}-\mathrm{P} / \mathrm{Au}$ stack.

Another way to make selective metallisation is the full-surface electroless copper deposition process, coupled with laser ablation. It consists in removing copper with a laser in the areas where copper is not required.

The third way is known as Plasmadust [4]: thanks to a pulsed arcing gas discharge, copper is able to be fixed on the surface of the plastic part. A mask is required to have selectivity.

Finally, the fourth way to make selective metallisation is the LDS process, developed and proposed by LPKF in Germany. Organometallic additives are integrated in the polymer material and their properties are modified by a laser beam after injection moulding of the parts. Then these parts are immersed in successive chemical plating bathes (copper, nickel and gold). During this process, metal is deposited only on the areas where the laser beam had activated the additive.

\subsection{Total plating}

In the case of the band diplexer demonstrator, metallisation using LDS process would require several unacceptable modifications of the part design to satisfy LDS design rules [5], and / or would complicate the laser activation process, which is not conform with the low cost production expectation. As selective plating is not required for this demonstrator, total plating is performed on this part (cheaper and more suited).

Standard total plating process is performed on the LCP Vectra E820i Pd parts, using the following process-flow:

- activation in basic chemical bath

- copper plating

The resulting quality of the surface does not meet the requirements of the demonstrator. Pitting on the surface may affect the ultimate conductivity of the joint. Deposited metal thickness also shows important variations depending on the location: from $6 \mu \mathrm{m}$ to $8 \mu \mathrm{m}$ for the copper layer. Surface roughness measurements, performed with an Olympus LEXT OLS 4000 confocal microscope, are not in agreement with the specifications.

In order to remove these defects, the total plating process-flow is optimized (see Fig. 3). A specific Pdbased coating is applied on the part before plating, resulting in more homogeneous copper thickness, without pitting. The coating increases the reactivity of the surface. The resulting metallised surface has a surface roughness of $\mathrm{Ra}=2.28 \mu \mathrm{m}$, which is in agreement with the targeted value.
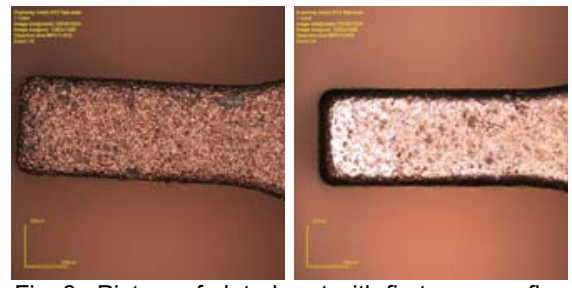

Fig. 3. Picture of plated part with first process flow on the left, and improved surface roughness on the right (confocal microscope)

\subsection{LDS process}

LDS process is used to selectively metallise the polymer cantilevers, enabling the electrical control of the MEMS mobile structure. The major challenge regarding the laser activation process is the position of the polymer surfaces to be activated: these faces are oriented at $0^{\circ}, 45^{\circ}$ and $90^{\circ}$ when the part is laying down under the laser source. In order to fit the design rules defined for LDS process (angle limit of $77,4^{\circ}$ ), a $45^{\circ}$ positioning tool is manufactured in order to enable the total activation of the cantilevers in a single step. This can be achieved because the maximal variation in the z-direction is below $6 \mathrm{~mm}$, which is compatible with the laser activation equipment.

Laser activation process is performed on the injected polymer parts using a LPKF Microline 3D 160iF. Recommended parameters for ABS/PC Xantar C RC 3710 LDS are used:

- laser beam speed: $2 \mathrm{~m} / \mathrm{s}$

- power: $4 \mathrm{~W}$

- frequency: $40 \mathrm{kHz}$

After laser activation, polymer parts are metallised with the following protocol:

- cleaning in commercial solution

- immersion in copper plating bath

- immersion in nickel plating bath

- immersion in gold flashing bath

Selective metallisation of ABS/PC parts using these process parameters offers satisfactory results in terms of metal thickness and surface roughness: $7,8 \mu \mathrm{m}(\mathrm{Cu})$. These values are in agreement with the specifications.

The same process is applied on ABS/PC parts, overmoulded with SEBS material. In this case, the SEBS is severely damaged during immersion in the gold flashing bath: the soft polymer material melts due to the temperature of chemical bath (immersion in a solution at $85^{\circ} \mathrm{C}$ for 10 minutes) (see Fig. 4).

In order to overcome this limitation, the processflow for MEMS package manufacturing is modified:

- injection moulding of the ABS/PC insert

- selective plating of the ABS/PC insert

- overmoulding of the metallised ABS/PC insert using SEBS material 


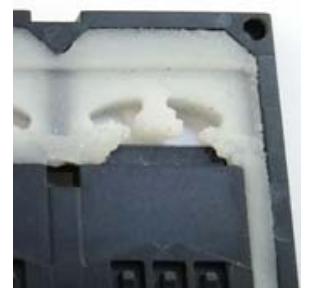

Fig. 4. Cover of the micro fluidic device (plating after overmoulding process). SEBS area is highly damaged.

This new process-flow prevents the SEBS material to face chemical solutions at high temperature (see Fig. 5). However, it involves the overmoulding of a metallised part. During the insertion of the metallised part in the mould cavity for overmoulding, the metallised areas can be damaged. Thus, surface quality of the metallised cantilevers is checked before and after SEBS overmoulding, with no noticeable variations. Indeed, roughness before overmoulding is $\mathrm{Ra}=6.07 \mu \mathrm{m}$, and this value is almost the same after overmoulding: $\mathrm{Ra}=6.17 \mu \mathrm{m}$.

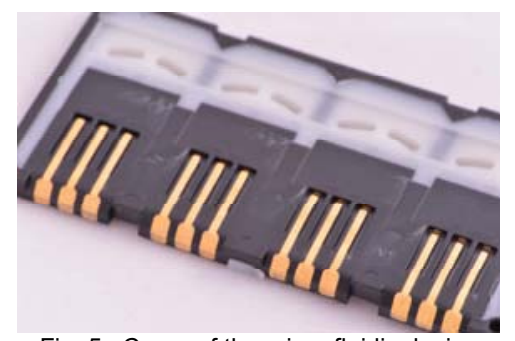

Fig. 5. Cover of the micro fluidic device

(overmoulding step after plating process step).

\section{Assembly}

For both demonstrators, the assembly is a critical process step. In the case of the MEMS packaging, it must ensure optimal air tightness. For the diplexer, the metallised cavity must be efficiently sealed to allow proper micro-waves processing.

Laser welding is performed on the MEMS package. The adequate selection of polymer materials enables the transmission of the laser beam energy through the transparent cover, and its absorption at the LDScompatible material surface. Laser used is a pulsed nanosecond fiber laser with a central wavelength of $1064 \mathrm{~nm}$. The laser pulse duration was set to $220 \mathrm{~ns}$ and a pulse energy of $28.3 \mu \mathrm{J}$ was used at a $300 \mathrm{kHz}$ frequency. The laser focal plane was offset resulting in a spot diameter of $150 \mu \mathrm{m}$ at the interface of the 2 housing parts. The distance between 2 pulses is equal to $2.3 \mu \mathrm{m}$ with a scanning speed of $700 \mathrm{~mm} / \mathrm{s}$.

A uniform pressure was applied on the clear top housing part and the laser irradiation was executed following the defined welding path.

Gluing is selected for the diplexer demonstrator. It was planned to glue the body and the lid. As it's crucial to have a very good contact between the 2 parts, it had been decided to make a glue path. It's a small groove with a complex 2D shape and a half cylinder section whose width is only $0.75 \mathrm{~mm}$. Some gluing trials were performed with a $3 \mathrm{D}$ printing machine to manage the glue deposit (see Fig. 6).

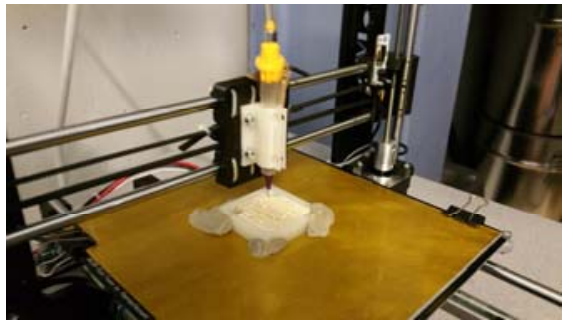

Fig. 6. Gluing trials performed with a 3D printing machine.

Unfortunately, adhesion of copper layer on LCP substrate is not satisfying, whatever the quality of the gluing joint between copper and copper. Alternative solution consists in removing selectively copper before gluing with a laser. It's a compact, high energy ultrafast fiber laser, operating at a central wavelength of $1032 \mathrm{~nm}$, with a pulse duration <400fs and pulse energy of $\sim 10 \mu \mathrm{J}$. The pulse frequency was set to $125 \mathrm{kHz}$ and the scanning speed to $500 \mathrm{~mm} / \mathrm{s}$, resulting in a pulse distance of $4 \mu \mathrm{m}$. The spot diameter at the focal plane was $35 \mu \mathrm{m}$. The copper removal track was repeated 7 times to ensure the complete and uniform removal of the copper layer. Highest breakout force was obtained with H20E Epo-Tek glue thanks to copper ablation: $253 \mathrm{~N}$ ( $10 \%$ better than without ablation).

\section{Conclusions}

An innovative combination of high throughput technologies for polymer processing and metallization has been developed and illustrated on two highly functional multi-material miniaturised devices. These results pave the way for a new generation of smart plastic products with enhanced functionalities.

Future developments will focus on the transfer of the demonstrated technologies in the frame of large industrial projects.

\section{Acknowledgements}

Hinmico is a European project supported through the Seventh Frame Program (FP7) under the "Factories of the Future" initiative. The research leading to these results has received funding from the European Community's FP7 (FP7/2013-11) under grant agreement $n^{\circ} 609110$. We thank EC for its support.

\section{References}

[1] Nan Zhang et al., "Towards nano-injection moulding”, Materials today, 2012, May, 216-221

[2] Prof. Dr.-Ing. Dr.-Ing. E.h. Walter Michaeli et al., "Injection molding of micro-structured surfaces", ANTEC, 2004, 752-756

[3] W.Eberhardt et al., "Polymer based multifunctional 3D-packages for Microsystems", 4M2006 proceedings, 2006, 67-70

[4] 3D-MID, "Manufacturing Process: Plasmadust", http://www.3d-mid.de/2/technology /manufacturing/plasmadust/plasmadust.html [5] LPKF website, "Design rules", http://www.Ipkf.com/applications/mid/designrules/index.htm 